\title{
DEVELOPMENT AND VALIDATION OF DAPAGLIFLOZIN BY REVERSED-PHASE HIGH-PERFORMANCE LIQUID CHROMATOGRAPHY METHOD AND IT'S FORCED DEGRADATION STUDIES
}

\author{
SHAKIR BASHA $\mathbf{S}^{1 *}$, SRAVANTHI $\mathbf{P}^{2}$ \\ ${ }^{1}$ Department of Pharmaceutical Analysis, Sree Vidyanikethan College of Pharmacy, Tirupati, Andhra Pradesh, India. ${ }^{2}$ Department of \\ Pharmacology, Sree Vidyanikethan College of Pharmacy, Tirupathi, Andhra Pradesh, India. Email: shakirbasha72@gmail.com
}

Received: 08 May 2017, Revised and Accepted: 13 July 2017

\section{ABSTRACT}

Objective: To develop and validate a simple, selective, precise, and accurate method for the estimation of dapagliflozin using reversed-phase highperformance liquid chromatography (RP-HPLC) technique in bulk and tablet formulation.

Methods: The proposed method utilizes chromatographic conditions hypersil BDS $(250 \mathrm{~mm} \times 4.6 \mathrm{~mm}, 5 \mu)$, mobile phase was buffer:acetonitrile (60:40) ratio, flow rate was maintained $1 \mathrm{ml} /$ minute, column temperature was set at $30^{\circ} \mathrm{C}$, detection wave length was $245 \mathrm{~nm}$, and diluent was mobile phase.

Results: By injecting 5 times of the standard solution system suitability parameters were studied, and results were found well under the acceptance criteria. The linearity study was performed by taking $25-150 \%$ levels, and the $\mathrm{R}^{2}$ value was found to be 0.999 , precision was found to be 0.5 for repeatability and 0.31 for intermediate precision. The \% recovery was found to be $99.89 \%$. Limit of detection and limit of quantitation were found to be $0.60 \mu \mathrm{g} / \mathrm{ml}$ and $1.81 \mu \mathrm{g} / \mathrm{ml}$, respectively. The $\%$ purity was found to be $99.71 \%$. Degradation study on dapagliflozin was performed and concluded that the purity threshold was more than purity angle and within the acceptable range.

Conclusion: The developed RP-HPLC method for dapagliflozin was found to be simple, precise, accurate, reproducible, and cost effective. Statistical analysis of the developed method conforms that the proposed method is an appropriate and it can be useful for the routine analysis. This method gives the basic idea to the researcher who is working in area such as product development and finish product testing.

Keywords: Dapagliflozin, High-performance liquid chromatography, System suitability, Repeatability, Purity threshold.

(c) 2017 The Authors. Published by Innovare Academic Sciences Pvt Ltd. This is an open access article under the CC BY license (http://creativecommons. org/licenses/by/4. 0/) DOI: http://dx.doi.org/10.22159/ajpcr.2017.v10i11.19705

\section{INTRODUCTION}

Dapagliflozin is a novel inhibitor of renal sodium-glucose cotransporter 2, which allows an insulin-independent approach to improve Type-II diabetes hyperglycemia [1]. It is a C-aryl glucoside derivative and is chemically known as (1s)-1, 5 -anhydro-1-C-[4-chloro3-[(4-ethoxyphenyl) methyl] phenyl]-D- glucitol (Fig. 1).

As per the past literature review, dapagliflozin was estimated by different chromatographic methods such as liquid chromatographymass spectrometry [2], normal phase high-performance liquid chromatography (HPLC) [3,4], and reversed-phase HPLC (RPHPLC) for simultaneous determination $[5,6]$ and by different spectroscopic methods such as ultraviolet (UV) [7], UV first derivative spectroscopy [6,8], and moreover several methods were there for the determination of its pharmacologic action [9-15].

Hence, the present paper reports that to develop and validate an accurate method for the estimation of dapagliflozin by RP-HPLC method and its forced degradation studies using a different mobile phase ratio that is a mixture of orthophosphoric acid buffer and acetonitrile in (60:40). Through this study, it was found that the mobile phase ratio showed effective results.

\section{METHODS}

Chemicals and reagents

Dapagliflozin was obtained as gift sample from Manus Aktteva Biopharma, Gujarat. Acetonitrile, methanol, and water used were of HPLC grade.
Selection of wavelength

Wavelength for detection was selected by obtaining absorption spectra of dapagliflozin in methanol using double beam UV-visible spectrophotometer. The spectrum of dapagliflozin in UV range was showed in Fig. 2 and concluded that dapagliflozin shows strong absorption at $245 \mathrm{~nm}$.

\section{Instrumentation}

Chromatography was performed on Waters HPLC 2996 system with Empower- 2 Software, equipped with a photodiode array detector (PDA) detector and chromatographic separation was performed using BDS column $(250 \times 4.6 \mathrm{~mm}, 5 \mu)[16]$.

\section{Chromatographic conditions}

An HPLC system (make:waters, model 2996) which is operated using a Software Empower - 2, fitted with BDS column and PDA detector (at $245 \mathrm{~nm}$ ) was used for the analysis. Gradient run with a flow rate $1 \mathrm{ml} /$ minute, temperature $30^{\circ} \mathrm{C}$ and injection volume $10 \mu \mathrm{l}$ was preferred for resolving the drug.

Preparation of mobile phase

A mixture (60:40) of orthophosphoric acid buffer and acetonitrile was used as mobile phase.

\section{Buffer preparation}

About $1 \mathrm{ml}$ of concentration orthophosphoric acid was diluted to $1000 \mathrm{ml}$ with water.

Diluents

Initially, the drug was dissolved in methanol, and water HPLC grade was used as a diluent for further dilutions. 
Stock solution preparation

Weighed accurately about $10 \mathrm{mg}$ of dapagliflozin working standard and transferred into $10 \mathrm{ml}$ volumetric flask. To this $7 \mathrm{ml}$ of diluent was added and sonicated for 5 minutes. Further, volume made with the diluent.

\section{Standard solution preparation}

Weighed accurately about $10 \mathrm{mg}$ of dapagliflozin working standard and transferred into $10 \mathrm{ml}$ volumetric flask. To this $7 \mathrm{ml}$ of diluent was added, sonicated for 5 minutes and diluted to volume with diluent. Further diluted 1-10 ml with diluent.

\section{Sample preparation}

Crushed and powdered 20 tablets. Weighed and transferred equivalent to five tablets powder of the dapagliflozin into $50 \mathrm{ml}$ volumetric flask, $30 \mathrm{ml}$ of diluent was added, sonicated to dissolve for 15 minutes and diluted to volume with diluent. Further diluted the filtrate 1-10 ml with diluent.

\section{Assay of marketed formulation}

Assay of the marketed formulation was carried out by injecting sample corresponding to equivalent weight into HPLC system. Then, the percent purity was found by following formula, and the results were shown in Table 1.

$$
\begin{aligned}
& \text { Assay }=\frac{\text { Samplearea }}{\text { Standardarea }} \times \frac{\text { Standard dilution factor }}{\text { Sampledilution factor }} \times \\
& \frac{\text { AverageWt of tab }}{\text { Labelclaim }} \times \text { Potency of std } \times 100
\end{aligned}
$$

\section{Validation parameters}

The validation of an analytical method confirms the characteristics of the method to fulfill the requirements of the application domain. The method was validated according to the ICH guidelines for specificity, linearity, precision, recovery, and stability [17]

\section{System suitability}

A standard solution of dapagliflozin working standard was prepared as per procedure and injected 5 times into the HPLC system. Then, the system suitability parameters were evaluated from standard chromatograms obtained. The \% relative standard deviations (RSD) of retention time, tailing factor, theoretical plates, and peak areas from five

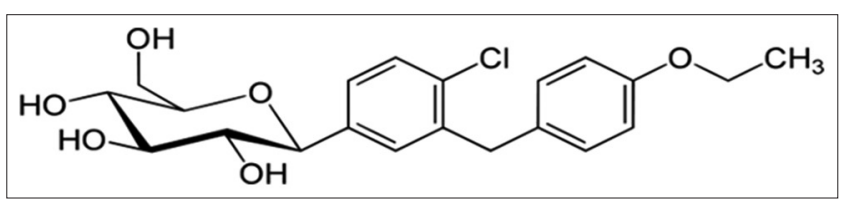

Fig. 1: Structure of dapagliflozin replicate injections was within range and results were shown in Table 2, and the chromatogram was shown in Fig. 3.

\section{Specificity}

Specificity is the ability of a method to discriminate between the intended analyte(s) and other components in the sample, to check whether there is placebo, blank, impurity, and degradants interference at analyte concentration. Volume of $10 \mu \mathrm{l}$ of working placebo sample solution was injected, and the chromatogram was recorded. Specificity graph was shown in Fig. 4.

\section{Linearity}

To demonstrate linearity of the assay method, five standard solutions with concentrations of about 25-150 ppm of dapagliflozin was injected. Then, a graph was plotted between concentrations and peak area. Linearity plot was shown in Fig. 5.

\section{Accuracy}

Three concentrations of $50 \%, 100 \%$, and $150 \%$ were injected in a triplicate manner then \% recovery and \% RSD were calculated and shown in Table 3.

Table 1: Assay of formulation: (Label claim: $10 \mathrm{mg}$ of dapagliflozin)

\begin{tabular}{llllll}
\hline Formulation & $\begin{array}{l}\text { Label } \\
\text { claim (mg) }\end{array}$ & Assay & Average & SD & \% RSD \\
\hline Dapagliflozin & 10 & 99.13 & 99.71 & 0.51 & 0.51 \\
Dapagliflozin & 10 & 99.46 & & & \\
Dapagliflozin & 10 & 99.32 & & & \\
Dapagliflozin & 10 & 100.46 & & & \\
Dapagliflozin & 10 & 99.75 & & & \\
Dapagliflozin & 10 & 100.12 & & & \\
\hline
\end{tabular}

SD: Standard deviation, RSD: Relative standard deviations

Table 2: System suitability parameters of dapagliflozin

\begin{tabular}{lllll}
\hline Peak name & RT & $\begin{array}{l}\text { USP plate } \\
\text { count }\end{array}$ & Peak area & USP tailing \\
\hline Dapagliflozin & 2.789 & 5030 & 736119 & 1.02 \\
Dapagliflozin & 2.796 & 5208 & 730712 & 1.02 \\
Dapagliflozin & 2.796 & 5013 & 734185 & 1.01 \\
Dapagliflozin & 2.797 & 5072 & 735891 & 1.01 \\
Dapagliflozin & 2.800 & 5134 & 731267 & 1.02 \\
Dapagliflozin & 2.810 & 5269 & 729905 & 1.01 \\
AVG & 733012 & & & \\
SD & 2731.3 & & & \\
\% RSD & 0.37 & & & \\
\hline
\end{tabular}

RSD: Relative standard deviations, SD: Standard deviations

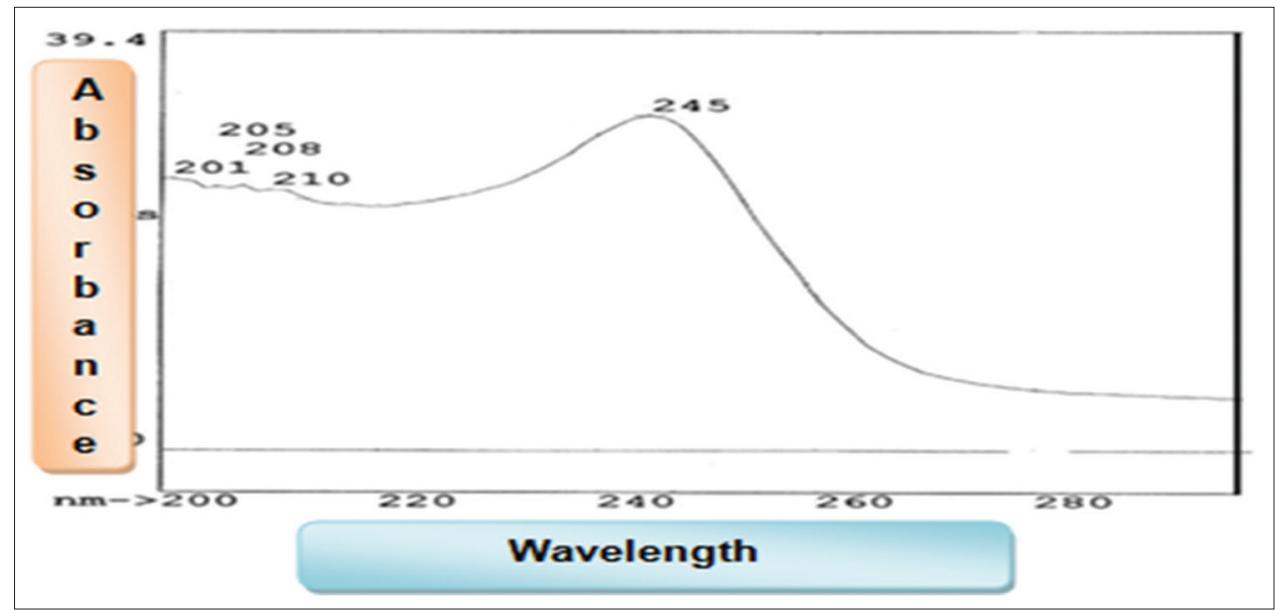

Fig. 2: Ultraviolet spectrum of dapagliflozin 


\section{Precision}

Precision was estimated by studying repeatability, intra- and interday tests by injecting $100 \mathrm{ppm}$ concentration of dapagliflozin. The results were calculated as standard deviation, relative standard deviation and shown in Table 4.

\section{Limit of detection (LOD)}

LOD is the lowest level of concentration of analyte in the sample that can be detected, though not necessarily quantitated. It can be calculated from the below formula, and the results are shown in Table 5 .

$\operatorname{LOD}=3.3 \sigma / \mathrm{S}$

Where,

$\sigma=$ Standard deviation of the response,

$\mathrm{S}=$ Slope of calibration curve.

\section{Limit of quantitation (LOQ)}

LOQ is the lowest concentration of analyte in a sample that may be determined with acceptable accuracy and precision when the required procedure is applied. It can be calculated from the below formula, and the results are shown in Table 6.

$\mathrm{LOQ}=10 \sigma / \mathrm{S}$

Where,

$\sigma=$ Standard deviation of the response,

$\mathrm{S}=$ Slope of calibration curve.



Fig. 3: System suitability chromatogram of dapagliflozin

\section{Robustness}

It is the capacity of the method to remain unaffected by small but deliberate variations in method parameters. The analysis was performed by slightly changing the temperature, mobile phase composition and flow rate. The results were calculated as \% RSD and were given in Table 7 .

\section{Degradation studies \\ Acid degradation studies}

To $1 \mathrm{ml}$ of stock solution of dapagliflozin, $1 \mathrm{ml}$ of $2 \mathrm{~N}$ hydrochloric acid was added and refluxed for 30 minutes at $60^{\circ} \mathrm{C}$. Then, the resultant solution was diluted to obtain $100 \mu \mathrm{g} / \mathrm{ml}$ solution. Then, $10 \mu \mathrm{l}$ solution was injected into the system. The chromatogram was recorded to assess the stability of sample which is shown in Fig. 6; \% of degradation was calculated and shown in Table 8.

\section{Alkali degradation studies}

To $1 \mathrm{ml}$ of stock solution dapagliflozin, $1 \mathrm{ml}$ of $2 \mathrm{~N}$ sodium hydroxide was added and refluxed for 30 minutes at $60^{\circ} \mathrm{C}$. Then, the resultant solution was diluted to obtain $100 \mu \mathrm{g} / \mathrm{ml}$ solution, and $10 \mu \mathrm{l}$ was injected into the system, and the chromatograms were recorded to assess the stability of sample which is shown in Fig. 6, \% of degradation was calculated and shown in Table 8.

\section{Oxidation degradation studies}

To $1 \mathrm{ml}$ of stock solution of dapagliflozin, $1 \mathrm{ml}$ of $20 \%$ hydrogen peroxide $\left(\mathrm{H}_{2} \mathrm{O}_{2}\right)$ was added separately. The solutions were kept for 30 minutes at $60^{\circ} \mathrm{C}$. Then, the resultant solution was diluted to obtain $100 \mu \mathrm{g} / \mathrm{ml}$ solution, and $10 \mu \mathrm{l}$ was injected into the system, and the chromatograms were recorded to assess the stability of sample which is shown in Fig. 6, \% of degradation was calculated and shown in Table 8.

\section{Thermal degradation studies}

The standard drug solution was placed in oven at $60^{\circ} \mathrm{C}$ for $6 \mathrm{hrs}$ to study dry heat degradation. Then, the resultant solution was diluted to $100 \mu \mathrm{g} / \mathrm{ml}$ solution, and $10 \mu \mathrm{l}$ was injected into the system, and the chromatograms were recorded to assess the stability of sample which is shown in Fig. 6, \% of degradation was calculated and shown in Table. 8.



Fig. 4: Specificity chromatogram of standard dapagliflozin

Table 3: Accuracy data

\begin{tabular}{|c|c|c|c|c|c|c|}
\hline Spiked concentration (\%) & Amount taken PPM & Amount recovered PPM & \% Recovery & Average & SD & $\%$ RSD \\
\hline 50 & 50 & 50.01 & 100.02 & & & \\
\hline 50 & 50 & 50.17 & 100.34 & 99.82 & 0.63 & 0.63 \\
\hline 50 & 50 & 49.55 & 99.11 & & & \\
\hline 100 & 100 & 100.30 & 100.30 & & & \\
\hline 100 & 100 & 99.84 & 99.84 & 100.00 & 0.26 & 0.26 \\
\hline 100 & 100 & 99.87 & 99.87 & & & \\
\hline 150 & 150 & 150.97 & 100.65 & & & \\
\hline 150 & 150 & 149.18 & 99.40 & 99.83 & 0.71 & 0.71 \\
\hline 150 & 150 & 149.17 & 99.45 & & & \\
\hline AVG & 99.89 & & & & & \\
\hline SD & 0.50 & & & & & \\
\hline$\%$ RSD & 0.50 & & & & & \\
\hline
\end{tabular}


Photo stability (UV) degradation studies

The photochemical stability of the drug was also studied by exposing the $100 \mu \mathrm{g} / \mathrm{ml}$ solution to UV light by keeping the beaker in UV Chamber for 7 days or 200 Watt hrs $/ \mathrm{m}^{2}$ in photo stability chamber. For HPLC study, from this, $10 \mu \mathrm{l}$ was injected into the system, and the chromatograms were recorded to assess the stability of sample which is shown in Fig. 6, $\%$ of degradation was calculated and shown in Table 8.

\section{Neutral (water) degradation studies}

Stress testing under neutral conditions was studied by refluxing the drug in water for $6 \mathrm{hrs}$ at a temperature of $105^{\circ} \mathrm{C}$. For HPLC study, the resultant solution was diluted to $100 \mu \mathrm{g} / \mathrm{ml}$ solution and $10 \mu \mathrm{l}$ was injected into the system and the chromatograms were recorded to assess the stability of sample which is shown in Fig. 6, \% of degradation was calculated and shown in Table 8.

\section{RESULTS AND DISCUSSION}

The selected drug dapagliflozin was estimated by RP-HPLC method and the forced degradation studies were performed as per ICH Guidelines. The method was optimized in the mobile phase ratio of Buffer (Ortho phosphoric acid buffer): Acetonitrile (60:40). The detection was carried out at the wavelength of $245 \mathrm{~nm}$ (shown in Fig. 2) with a retention time $2.789 \mathrm{~min}$ and with peak asymmetry of 1.02 (shown in Fig. 3 and Table 2).

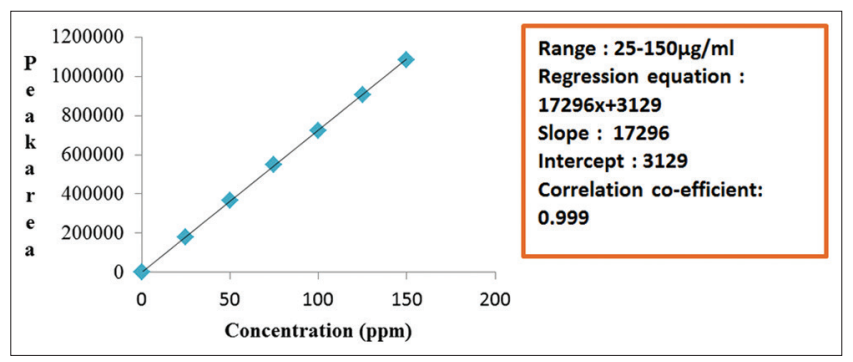

Fig. 5: Linearity plot of dapagliflozin
The method was validated as per ICH guidelines. The linearity range for Dapagliflozin was $25-150 \mu \mathrm{g} / \mathrm{ml}$ with $\mathrm{R}^{2}$ (correlation co-efficient) value of 0.999 (shown in Fig. 5). The percentage RSD for method and system precision was $<2 \%$ (shown in Table 2). The method has been validated in assay of dosage forms. The accuracy of the method was validated by recovery studies and was found to significant and under specification limits, with \% Recovery 99.11- 100.65 \% (within acceptable range (98$102 \%$ ) (shown in Table 3). The assay results were found to be $99.71 \%$ (shown in Table 1) (i.e., within 98-102\%). LOD and LOQ were found to be $0.60 \mu \mathrm{g} / \mathrm{ml}$ and $1.81 \mu \mathrm{g} / \mathrm{ml}$ respectively (Table 5 and Table 6). The method also passes the specifications for robustness parameters (shown in Table 7).

The sample solutions were subjected to acid, base, oxidative, thermal, UV, Neutral degradations. The \% degradation in acid (7.35 \%), basic

Table 4: Precision reports for dapagliflozin

\begin{tabular}{llll}
\hline Precision & SD & \% RSD & Acceptance limit \\
\hline System precision & 2431.1 & 0.34 & NMT 2\% \\
Repeatability & 3608.3 & 0.5 & NMT 2\% \\
Intermediate precision & 2156.2 & 0.31 & NMT 2\% \\
\hline
\end{tabular}

RSD: Relative standard deviations, SD: Standard deviations

Table 5: LOD of dapagliflozin

\begin{tabular}{llll}
\hline Drug name & SD & Slope & LOD $(\mu \mathrm{g} / \mathbf{m l})$ \\
\hline Dapagliflozin & 3129 & 17296 & 0.60 \\
\hline
\end{tabular}

SD: Standard deviation, LOD: Limit of detection

Table 6: LOQ of dapagliflozin

\begin{tabular}{llll}
\hline Drug name & SD & Slope & LOQ $(\mu \mathrm{g} / \mathrm{ml})$ \\
\hline Dapagliflozin & 3129 & 17296 & 1.81 \\
\hline
\end{tabular}

SD: Standard deviation, LOQ: Limit of quantification



Fig. 6: Degradation studies of dapagliflozin 
Table 7: Robustness data of dapagliflozin

\begin{tabular}{|c|c|c|c|c|c|c|c|}
\hline Parameter & Modification (ml/minutes) & RT & USP plate count & USP tailing & Peak area & SD & $\%$ RSD \\
\hline \multirow[t]{3}{*}{ Flow rate } & 0.9 & 3.141 & 6646 & 1.05 & 721537.9 & 7083.5 & 0.98 \\
\hline & 1.0 & 2.780 & 6846 & 1.19 & 772345.6 & & \\
\hline & 1.1 & 2.580 & 5853 & 1.02 & 635920.4 & & \\
\hline \multirow[t]{3}{*}{ Change in mobile phase ratio } & $50: 50$ & 2.679 & 6102 & 1.03 & 685932.8 & 3428.4 & 0.07 \\
\hline & $60: 40$ & 2.832 & 6543 & 1.16 & 724563.7 & & \\
\hline & $55: 45$ & 3.011 & 6270 & 1.13 & 716432.5 & & \\
\hline \multirow[t]{3}{*}{ Temperature } & $25^{\circ} \mathrm{C}$ & 2.780 & 6298 & 1.02 & 716014.6 & 3235.6 & 0.45 \\
\hline & $30^{\circ} \mathrm{C}$ & 2.782 & 6743 & 1.04 & 724634.7 & & \\
\hline & $35^{\circ} \mathrm{C}$ & 2.763 & 6410 & 1.02 & 659511.6 & & \\
\hline
\end{tabular}

RSD: Relative standard deviations, SD: Standard deviations

Table 8: Results of degradation data of dapagliflozin

\begin{tabular}{lllll}
\hline Degradation condition & Exposure & Time & \% Drug degraded & Purity angle \\
\hline Acid & $2 \mathrm{~N} \mathrm{HCl} / 60^{\circ} \mathrm{C}$ & 30 minutes & 7.35 & 0.115 \\
Alkali & $2 \mathrm{~N} \mathrm{NaOH} / 60^{\circ} \mathrm{C}$ & 30 minutes & 6.90 & 0.311 \\
Oxidation & $20 \% \mathrm{H}_{2} \mathrm{O}_{2} / 60^{\circ} \mathrm{C}$ & 30 minutes & 5.53 & 0.361 \\
Thermal & $\mathrm{At} 60^{\circ} \mathrm{C}$ & $6 \mathrm{hrs}$ & 4.43 & 0.361 \\
UV & $\mathrm{UV} \mathrm{chamber}$ & 7 days & 1.91 & 0.271 \\
Water & At room temp & 6 hrs & 0.78 & 0.113 \\
\hline
\end{tabular}

UV: Ultraviolet

(6.90\%), oxidative $(5.53 \%)$, hydrolytic $(0.78 \%)$, thermal $(4.43 \%)$, photolytic (1.91\%) was found (shown in Table 8).

\section{CONCLUSION}

The developed RP-HPLC method for dapagliflozin was found to be simple, precise, accurate, reproducible, and cost effective. Statistical analysis of the developed method conforms that the proposed method is an appropriate and it can be useful for the routine analysis. This method gives the basic idea to the researcher who is working in area such as product development and finish product testing. The developed method can also be used regular for the in-process quality control of the sample. This method gives the sound knowledge about stability studies. The results of the forced degradation studies show the major route of degradation is in acid hydrolysis followed by alkali, oxidation, thermal, photolytic, and neutral, respectively. The developed method concludes that the dapagliflozin was found to be stable in neutral, photolytic, thermal and oxidative stress conditions, and unstable in acidic and alkali conditions.

\section{ACKNOWLEDGMENT}

The author thanks the management and the Principal of Sree Vidyanikethan College of Pharmacy, for providing the infrastructure and their support to carry out the research work

\section{REFERENCES}

1. List FJ, Woo V, Morales E, Tang W, Fiedorek FT. Sodium-glucose cotransport inhibition with dapagliflozin in Type 2 diabetes. Diabetes care 2009;32(4):650-7.

2. Aubry AF, Gu H, Magnier R, Morgan L, Xu X, Tirmenstein M, et al. Validated LC-MS/MS methods for the determination of dapagliflozin, a sodium-glucose co-transporter 2 inhibitor in normal and ZDF rat plasma. Bioanalysis 2010;2(12):2001-9.

3. Yunoos M, Sankar DG. A validated stability indicating highperformance liquid chromatographic method for simultaneous determination of metformin HCL and dapagliflozin in bulk drug and tablet dosage form. Asian J Pharm Clin Res 2015;8(3):0974-2441.

4. Gaware D, Patil RN, Harole M. A validated stability indicating RPHPLC method for simultaneous determination of metformin and canagliflozinin pharmaceutical formulation. World J Pharm Pharm Sci 2015;4(12):631-40.

5. Bhoomaiah B, Shree AJ. Development and validation of RP-HPLC method for simultaneous determination of metformin and miglitol in bulk and pharmaceutical formulation. Int $\mathrm{J}$ Pharm Pharm Sci
2014;6(6):0975-1491

6. Manasa S, Dhanalakshmi K, Reddy GN, Sreenivasa S. Method development and validation of dapagliflozin in API by RPHPLC and UV-spectroscopy. Int J Pharm Sci Drug Res 2014;6(3):250-2.

7. Jani BR, Shah KV, Kapupara PP. Development and validation of UV spectroscopic method for simultaneous estimation of dapagliflozin and metformin hydrochloride in synthetic mixture. Int J Res Dev Pharm Life Sci 2015;4(3):1569-76.

8. Jani BR, Shah KV, Kapupara PP. Development and validation of UV spectroscopic first derivative method for simultaneous estimation of dapagliflozin and metformin hydrochloride in synthetic mixture. J Bioequiv Stud 2015;1(1):102.

9. van der Walt JS, Hong Y, Zhang L, Pfister M, Boulton DW, Karlsson MO. A nonlinear mixed effects pharmacokinetic model for dapagliflozin and dapagliflozin 3-O-glucuronide in renal or hepatic impairment. CPT Pharmacometrics Syst Pharmacol 2013;2:e42.

10. Tatarkiewicz K1, Polizzi C, Villescaz C, D’Souza LJ, Wang Y, Janssen S, et al. Combined antidiabetic benefits of exenatide and dapagliflozin in diabetic mice. Diabetes Obes and Metab 2014;16(4):376-80.

11. Kohan DE, Fioretto P, Tang W, List JF. Long-term study of patients with Type 2 diabetes and moderate renal impairment shows that dapagliflozin reduces weight and blood pressure but does not improve glycemic control. Kidney Int 2014;85(4):962-71.

12. Reilly TP, Graziano MJ, Janovitz EB, Dorr TE, Fairchild C, Lee F, et al. Carcinogenicity risk assessment supports the chronic safety of dapagliflozin, an inhibitor of sodium-glucose co-transporter 2 , in the treatment of Type 2 diabetes mellitus. Diabetes Ther 2014;5(1):73-96.

13. Jadoon K, Idris I. Dapagliflozin: A once-daily oral therapy sodiumglucose cotransporter-2 inhibitor for the treatment of adult patients with Type 2 diabetes. Clinical medicine insights: Therapeutics 2011;3:185-94.

14. Lambers Heerspink HJ, de Zeeuw D, Wie L, Leslie B, List J. Dapagliflozin a glucose-regulating drug with diuretic properties in subjects with Type 2 diabetes. Diabetes Obes Metab 2013;15(9):853-62.

15. Ferrannini E, Ramos SJ, Salsali A, Tang W, List JF. Dapagliflozin monotherapy in Type 2 diabetic patients with inadequate glycemic control by diet and exercise a randomized, double-blind, placebocontrolled, phase 3 trial. Diabetes Care 2010;33(10):2217-24.

16. Jayaprakash R, Natesan SK. Stability indicating RP-HPLC method development and validation for the simultaneous determination of Vildaglipin and Metformin in pharmaceutical dosage form. Int J Pharm Pharm Sci 2017;9(3):150-7.

17. Dasgupta S, Dey S, Pal P, Mazumder B. RP-HPLC method development, validation, and quantification of Lornoxicam in lipid nanoparticle formulations. Int J Pharm Pharm Sci 2016;8(11):152-8. 